\title{
Exploratory Study of Social CRM use in SMEs
}

\author{
Marjeta Marolt ${ }^{1}$, Hans-Dieter Zimmermann², Andreja Pucihar ${ }^{3}$ \\ ${ }^{1,3}$ University of Maribor \\ Kidriceva cesta 55 a 4000 Kranj, Slovenia \\ E-mail.marjeta.marolt@fov.uni-mb.si,andreja.pucihar@fov.uni-mb.si
}

${ }^{2}$ FHS St. Gallen University of Applied Sciences

Rosenbergstrasse 59, Postfach 9000 St. Gallen, Switzerland

E-mail.hansdieter.zimmermann@fhsg.ch

cross $^{\text {ref }}$ http://dx.doi.org/10.5755/j01.ee.29.4.20246

\begin{abstract}
Social customer relationship management (social CRM) can enhance the performance of the enterprise through effective communication with customers and management of customer information. Whilst several studies have examined social CRM use from the perspective of large enterprises, relatively few have examined its use by micro, small and medium-sized enterprises (SMEs) which due to unique characteristics differ from large enterprises. The main objective of this paper is to provide a practical perspective on social CRM use in SMEs. This study applies a qualitative research approach by conducting six semi-structured interviews. To determine the antecedents of the intensity of social CRM, the dimensions of the intensity of social CRM use, as well as its impact on performance outcomes, a content analysis has been utilized. The findings reveal that social CRM use is complex; therefore, we propose a two-dimensional conceptualization of the intensity of social CRM use. Furthermore, this study identifies antecedents, which appears to influence the intensity of social CRM use, including relative advantages, compatibility, top management support, organizational culture, technology readiness and external pressure. This study also implies that more intensive use of social CRM appears to improve performance outcomes. Considering the findings, the recommendations for future research are provided.
\end{abstract}

Keywords: Social CRM; Intensity of Use; Antecedents; Performance Outcomes; Micro; Small and Medium-Sized Enterprises.

\section{Introduction}

The continuous evolution of the internet and the emergence of new digital technologies, especially social media (SM) (see, e.g. Kaplan \& Haenlein, 2010) is challenging the traditional relationship between enterprises and customers (Lobato, Pinheiro, Jacob, Reinhold, \& Santana, 2017). Traditionally, customers were predominantly passive receivers of distributed messages, and businesses had almost complete control over their brands. With the rise of SM (especially social networking sites, blogs, and content communities) the flow of information about a brand has become multidirectional, interconnected, and difficult to predict (Hennig-Thurau, Wiertz, \& Feldhaus, 2015). Enterprises have recognized SM as a means for maintaining relationships with their customers (Trainor, 2012). For example, they can listen to and engage with their customers as well as encourage them to become brand advocates (Vohra \& Neha, 2016). Some of them even manage to engage customers in the co-design processes of new products and services (Sigala, 2012).

Despite the increasing interest in SM (Kumar, Choi, \& Greene, 2016), understanding of how enterprises exploit SM use for CRM is still incomplete (Harrigan, Soutar, Choudhury, \& Lowe, 2015). Most of the research so far has been focused on the investigation of social CRM adoption and its use in large enterprises (Harrigan \& Miles, 2014). Even though several studies on social CRM (e.g. Harrigan et al., 2015; Trainor, Andzulis, Rapp, \& Agnihotri, 2014) adapted constructs used in previous studies (e.g.
Jayachandran, Sharma, Kaufman, \& Raman, 2005; Srinivasan \& Moorman, 2005) and developed new measures based on extensive literature review, researchers observed that some constructs did not perform as expected. Furthermore, some studies (e.g. Ahani, Rahim, \& Nilashi, 2017; Sigala, 2011) were focused on antecedents of the intensity of social CRM use, while others (e.g. Choudhury \& Harrigan, 2014; Trainor et al., 2014) were focused on the impact of the intensity of social CRM use on performance outcomes.

While CRM supported by sophisticated technologies is common in large enterprises, there is an evidence that SM has become an important technology that facilitates CRM activities in small enterprises (Malthouse, Haenlein, Skiera, Wege, \& Zhang, 2013; Trainor et al., 2014). According to Harrigan \& Miles (2014), SM may be the most appropriate CRM technology for micro, small and medium-sized enterprises (SMEs), mostly because SM seem to fit with their intuitive way of managing customer relationships. In addition, SMEs can afford these technologies due to their lower cost of implementation compared to traditional CRM technologies. With SM adoption and use, SMEs can reach the global market with minimal costs and efforts and bring their customers closer to their business (Cappuccio, Kulkarni, Sohail, Haider, \& Wang, 2012). Even though SMEs seem to be aware of several SM opportunities, they usually do not have formally defined SM strategies and mainly use SM as an additional marketing channel (SURS, 2013). These facts often result in a low-intensity of social CRM use, lost opportunities on the market, and lower 
competitiveness of SMEs. As SMEs are struggling to manage relationships with customers in different ways, using different SM and CRM technologies, researchers are trying to focus on offering conceptual clarity to the social CRM practices.

Furthermore, SMEs are considered as a key for economic growth, innovation, employment and social integration in the European Union (Airaksinen, Luomaranta, Alajaaskö, \& Roodhuijzen, 2015). While SMEs often have limited resources, expertise and impact in the marketplace (Durkin, McGowan, \& McKeown, 2013; Harrigan \& Miles, 2014) their social CRM adoption and use might differ from large enterprises (Harrigan, Ramsey, \& Ibbotson, 2009).

Considering the presented knowledge gaps, there is a need for further investigation of current practices of social CRM use, especially in the context of SMEs. More specifically, a comprehensive overview of social CRM phenomenon from the perspective of its antecedents, the intensity of use and its impact on performance outcomes with a focus on SMEs should be further investigated. The scientific problem in this paper is addressed by research questions: (1) How intensively do SMEs use social CRM?, (2) What are the antecedents influencing the intensity of social CRM use?, (3) What are the implications of the intensity of social CRM use?

While there is a lack of consensus on social CRM use construct dimensionality, the basic research aim of this study is to provide theoretical clarity on the construct. Furthermore, the research aim is also to examine antecedents and outcomes of social CRM use in the context of SMEs to achieve more comprehensive overview on social CRM phenomenon.

In order to achieve the formulated aims of the study, the following research objectives were being undertaken in the study: first, to gain deeper insights into the use of social CRM in SMEs; second, to provide a conceptual clarity of the intensity of social CRM use in SMEs; third, to identify antecedents determining the intensity of social CRM use; and fourth, to indicate the impact of intensity of social CRM use on performance outcomes.

For the purpose of this study, a case study research method was applied. First, the relevant literature was analysed, then six semi-structured interviews with selected Slovenian SMEs, with different practices of social CRM use, were conducted. Based on the content analysis and consistent with previous research (Harrigan et al., 2015; Jayachandran et al., 2005; Reinartz, Krafft, \& Hoyer, 2004), this study proposes a process-based conceptualization of social CRM use. In particular, our conceptualization of social CRM emphasizes the utilization of social CRM for two main processes: communication with customers and management of customer data and information (Harrigan \& Miles, 2014). These findings and findings regarding antecedents and performance outcomes are discussed in the context of existing body of literature.

The rest of the paper is structured as follows. The next section discusses previous research on social CRM. Then the method used in this research is presented and findings discussed. Finally, the limitations and recommendations for further research are presented.

\section{Theoretical Background}

Social CRM is a relatively new concept which was evoked by the rise of SM for business in 2007 (Greenberg, 2010). Based on the academic and practitioners' literature it appears that social CRM is an extension, not the replacement, of traditional CRM (Yawised, Marshall, \& Stockdale, 2013). Social CRM builds on the foundation of traditional CRM and utilizes SM technologies for better customer relationship management (Faase, Helms, \& Spruit, 2011). Technology presents a vital of the successful CRM but does not necessarily require sophisticated technologies (Boulding, Staelin, Ehret, \& Johnston, 2005). Nevertheless, these technologies need to facilitate the underlying marketing and customer-centric strategies (Jayachandran et al., 2005). According to Harrigan et al., 2015, there are two principal areas in which technology can enable CRM: customer communication and customer information management. The basic aim of every technology (from simple technologies such as websites, email, SM and databases to more sophisticated technologies such as for example Salesforce CRM) used for CRM is to build customer insights and use them to better tailor products or services as well as communications to customers.

\section{Intensity of Social CRM Use}

This study considers the intensity of social CRM use as an enterprise ability to leverage SM technologies in combination with other CRM technologies to systematically manage relationships with customers. Similar to the concepts of customer-facing CRM processes and relational information processes defined by Jayachandran et al. (2005) and Reinartz et al., (2004) intensity of social CRM use refers to enterprise ability to generate, integrate, and respond to information obtained from customer interactions that are facilitated by SM technologies (Trainor et al., 2014).

Reinartz et al. (2004) suggest conceptualization of CRM intensity through customer-facing processes, consisting of three processes: customer initiation, customer maintenance, and customer termination. Following this suggestion, several researchers have investigated CRM through customer-facing processes (e.g. Malthouse et al., 2013; Sigala, 2011), using slightly different characterizations of these processes. According to social CRM research (Malthouse et al., 2013; Sigala, 2011), the first customerfacing process is customer acquisition where the awareness is created and changes in attitudes among prospective customers are observed. In the customer retention process (second customer-facing process), an enterprise tries to retain existing customers and maintain relationships with them. According to Kim (2012), the customer termination process is not the last customer-facing processes because it is rarely conducted in the real situation. Instead, the customer expansion process is suggested as a third customer-facing process. In this process, an enterprise is engaged in cross-selling and up-selling activities, and in active interactions with customers (e.g. asking for frequent feedback and/or for contribution to a new product or service development; participation in online communities and user 
groups). While Malthouse et al. (2013) proposed a comprehensive "social CRM house" framework that includes customer-facing processes, Sigala (2011) has studied how SM are used through customer-facing processes in Greek tourism enterprises and noticed the unbalanced exploitation of SM in customer-facing processes. Her findings showed that there are several antecedents that affect the intensity of social CRM use.

Reinartz et al. (2004) model consists of different subdimensions in each primary dimension (relationship initiation, maintenance, and termination). Customer evaluation is considered as the first sub-dimension of each primary dimension. Choudhury \& Harrigan (2014) suggested different conceptualization. They have used Jayachandran et al. (2005) CRM model as the foundation for their study and added 'customer engagement initiatives' as a new construct. Jayachandran et al. (2005) concept was introduced for detail exploration of customer information processes, comprising of information capture, information integration, information access and information use dimensions. These dimensions are similar to customer evaluation sub-dimension suggested by Reinartz et al. (2004). Separating customer evaluation subdimension from primary dimensions suggested by Reinartz et al. (2004) seems to be reasonable since many SMEs are doing business with customers intuitively (Harrigan \& Miles, 2014). Moreover, SMEs often do not have enough of resources for assimilation of customer information into a holistic view. In addition, Choudhury \& Harrigan (2014) argued that customer engagement initiatives construct (comprising the dimensions of communication with customers, online customer communities, management of online customer communities and mobile technologies) on its own is not sufficient. Hence, they suggest that the interrelationship between relational information processes and customer engagement should be taken into consideration. Furthermore, more emphasis should be given on customer engagement construct (Sashi, 2012).

\section{Antecedents of Social CRM Use}

The organizational adoption and use of social CRM has been examined by several authors, taking into consideration adoption antecedents both within and outside the business unit (e.g. Askool \& Nakata, 2011; Harrigan \& Miles, 2014; Mousavi \& Demirkan, 2013; Sigala, 2011). The antecedents of social CRM use can be classified either as technological, organizational or environmental. This classification is consistent with technology, organization, and environment (TOE) framework proposed by Tornatzky \& Fleischer (1990). While TOE framework is highly adaptable, several researchers have combined it with other theories (e.g. diffusion of innovation (DOI), institutional theory, Iacovou, Benbasat, \& Dexter (1995) theory) (Oliveira \& Martins, 2011). Combination of DOI theory and TOE framework offers a more holistic model for explanation of organizational behaviour (Oliveira \& Martins, 2011).

The antecedents that represent the core pillars of DOI theory (relative advantage, complexity, compatibility, trialability, and observability), have been examined in the CRM adoption literature and have been used in the technological context of TOE framework in previous research (e.g. Hasani, Bojei, \& Dehghantanha, 2017; Law, Ennew, \&
Mitussis, 2013). There are also other antecedents that have been used in the technological context of TOE framework, as for example cost of adoption (Ahani et al., 2017), vendor support dimension (Alshawi, Missi, \& Irani, 2011), that will also be considered in this study. In the organizational context of TOE framework different antecedents have been found in the CRM adoption literature, including technology competence (Ahani et al., 2017; Alshawi et al., 2011), top management support (Ahani et al., 2017; Alshawi et al., 2011; Hasani et al., 2017), and innovation orientation (Law et al., 2013; Sophonthummapharn, 2009) to name a few. Even though less research considered antecedents related to the environmental context (Premkumar, 2003) several CRM studies have found that they have an influence on innovation adoption (e.g. Hasani et al., 2017; Sophonthummapharn, 2009). For example, customer pressure, competitive pressure, and government support have been considered in the related literature (Ahani et al., 2017; Hasani et al., 2017; Sophonthummapharn, 2009).

\section{Performance Outcome of Social CRM Use}

As already mentioned, SM present important technologies for managing relationships with customers and can help SMEs to achieve higher business performance in many aspects (Harrigan, 2011; Trainor et al., 2014). For example, enterprises have the ability to interact in real-time with customers, also on a one-to-one basis, they can promote their products and services more quickly and efficiently, and they can even reduce the operating cost (McCann \& Barlow, 2015). For that reasons enterprises are increasingly using SM in their everyday business activities and exploiting potentials to gain competitive advantages (Stelzner, 2016). However, for enterprises, the simple introduction of SM is not sufficient. They need to ensure that SM are used effectively. This can only be achieved through strategic approach with clearly defined objectives and evaluation metrics with defined key performance indicators (McCann \& Barlow, 2015).

Performance outcomes can be generally classified into customer performance and business performance (Kim \& $\mathrm{Kim}, 2009)$. However, recent research on social CRM tends to measure predominantly customer-related outcomes (Harrigan et al., 2015; Trainor et al., 2014). For example, Trainor et al. (2014) assessed the extent to which enterprises are successful at satisfying and retaining loyal customers. Similarly, Harrigan et al. (2015) defined performance as customer satisfaction and loyalty, however, they found that these measures do not appear to be completely adequate in social CRM studies. Therefore, further refinements of customer relationship performance measures are suggested.

\section{Methodology}

First, a literature review was conducted using various databases such as Science Direct, Scopus, and Google Scholar. As the aim of this research was to elicit rich information about the intensity of social CRM use, antecedents that influence the intensity of social CRM use and its impact on performance outcomes, the interview was perceived to best serve the purpose of this study. 


\section{Case Selection}

The SMEs participating in the study were purposefully selected in order to provide a wide range of perspectives on social CRM practices. As such, Slovenian SMEs from private sectors that represent different sizes and were exhibiting best social CRM practices were chosen.

The targeted SMEs were contacted through e-mails and Facebook messenger. From 15 selected SMEs a total of six SMEs' managers/owners agreed to participate. Small sample sizes are usual in studies developing a theoretical model for further research (Salciuviene, Hopeniene, \& Dovaliene, 2016). Furthermore, according to Morse (1994) in the case of the phenomenological study, at least six participants are recommended. The following paragraphs present participating SMEs.

The creative studio is a micro-enterprise that produces unique clothes for children. The enterprise sells products in Slovenia through its Facebook site and through different fairs organized around the country.

The pet supply store is a micro-enterprise with one store located in Ljubljana, the capital city of Slovenia. They have a website and web store. Customers can obtain information about new and existing products on Facebook or Twitter. They also use a forum in which they discuss and help their customers with problems they have with their pets.

The catering provider is a small enterprise, which uses the Salesforce CRM, has a website and is very active on SM. They are present on Facebook, LinkedIn, TripAdvisor, Pinterest, Instagram, and Google+. For each brand, they also have a separate Facebook page (altogether seven pages).

The sporting goods retailer is the small enterprise that sells sporting goods across Slovenia through web store and local stores. They are active on Facebook, Instagram, and Pinterest and use Google Analytics to measure conversion between SM and their web store.

The retailer that sells fashion goods over a network of stores is a medium-sized enterprise without a web store. They have several Facebook sites and are also present on Instagram. The community management via SM is outsourced. The enterprise does not use any specialized CRM system.

The cosmetics producer and retailer is a medium-sized enterprise. The cosmetics that the enterprise produces are mainly sold to other retailers such as supermarket chains. They also act as a distributor for several brands such as Bolsius, Revlon, Moroccanoil. The enterprise has the web store where it sells the best-selling products in the world of cosmetics to end customers. They mainly communicate with their end users via SM (Facebook, Instagram) and have a separate Facebook page for their most successful brands.

\section{Data Collection}

As regards to the data collection technique, the semistructured interview approach was used. It was chosen mainly because this approach allows the researchers to use a predetermined set of open-ended questions and it offers a high level of flexibility in identifying new potential issues related to the investigated research phenomenon (Daymon $\&$ Holloway, 2010). The questionnaire included questions such as: how your enterprise is using social CRM for managing customer relationships, how you manage customer data gathered from different online and offline channels, what are the main factors influencing the increase of exploitation level of social CRM, how does the exploitation level of social CRM impact on performance outcomes. This structured approach ensured a consistent interview structure across the enterprises. The participants were provided with the interview questions in advance. This allowed them to familiarise themselves with the content of the interview.

The interviews were done in person at the site of the case enterprises in the second half of 2016. The duration of each interview was between 55 and 90 minutes. Notes in conjunction with audio recordings were taken during the interview. Immediately after the interviews, further notes were compiled about the overall impression of the interviewer, and clean transcripts of the audio records were made.

\section{Data Analysis}

After the transcripts were verified by interviewees the data analysis started. First, the interview transcripts were carefully and thoroughly read and re-read. To be consistent as possible with the literature, the initial coding scheme was derived from theories and prior research and modified within the course of the analysis when new categories emerged inductively. After the clarification of codes and definitions with the research assistant, an interview transcript was selected randomly and a copy of it was coded by both researchers. After coding consistency was achieved, the coding scheme with coding rules was applied to all interview transcripts by one researcher. When all interview transcripts were coded, the coding consistency was rechecked. Then, the cross-case analysis was conducted to detect commonalities and differences in patterns of social CRM use across the studied cases. The results are discussed in the next section.

\section{Findings}

Based on literature review and exploratory, qualitative research the dimensions and specific sub-dimensions for the proposed dimension of the intensity of social CRM use construct were suggested. Furthermore, the antecedents influencing the intensity of social CRM use and the impact of the intensity of social CRM on the performance outcomes were indicated.

Overall, five out of six interviewed SMEs do not have an implemented SM strategy; two of them are considering its development as a next step. Only one SME has incorporated SM as a part of their digital marketing strategy. All of them are using built-in analytical services offered by SM platforms such as Facebook Analytics and Twitter Analyser. Some enterprises use also other tools provided by search engines such as Google Analytics. Surprisingly, none of the interviewed enterprises uses more comprehensive SM management tools (e.g. Hootsuite, Sprout Social) to manage multiple SM accounts. 


\section{Identified Dimensions for the Intensity of Social CRM Use}

According to the qualitative data analysis, interviewed SMEs are using SM to manage and build customer relations in each customer-facing process (customer acquisition, customer retention, and customer expansion). For instance, a digital marketing manager of cosmetic producer and retailer pointed out: "For one of our brands we have set up a digital marketing system, using Facebook, Instagram, and blog to engage with customers. Besides the promotional content, we post useful hints and tips and collect customers' opinions, tastes, or beliefs. While all interviewed SMEs explained the way how they manage customer information, they claimed that their SM activities are not strictly based on customer evaluation. For example, the owner of pet supply store stated: "We are using Google Analytics and Facebook Insights to gain some general knowledge about our followers. For each new follower, we also check their profile to see what kind of dog they have and what they are doing. But generally, we are still relying on our intuition when engaging with our customers." Based on these findings three new subdimensions emerged: information capture, information integration, and information use. While these new subdimensions were not aligned with customer-facing processes dimension they were merged into a new dimension relational information processes. Thus, according to the content analysis, the intensity of social CRM use consists of two dimensions. Table 1 provides examples of the CRM processes facilitated by social CRM.

Table 1

\section{Examples of CRM Processes Facilitated by Social CRM}

\begin{tabular}{|c|c|}
\hline CRM processes/sub-processes & Role of social CRM \\
\hline \multicolumn{2}{|l|}{ Customer-facing processes } \\
\hline Customer acquisition & $\begin{array}{l}\text { Generate discussion about the brand and relevant topics } \\
\text { Share stories about community involvement and fun activities that build brand } \\
\text { Activate brand ambassadors and opinion leaders in promotional activities } \\
\text { Educate the customer on product or service through the two-way interaction (e.g. Facebook messenger) } \\
\text { Generate visually compiling ad with a link to the web store } \\
\text { Invite followers to events, product testing, ... }\end{array}$ \\
\hline Customer retention & $\begin{array}{l}\text { Communicate success stories, innovations, past events etc. } \\
\text { Inform customers about special offers } \\
\text { Provide prompt correspondence to customer request, complaints (e.g. complaints handling) } \\
\text { Use mentions of your product/service/brand to promote yourself } \\
\text { Empower customers to help you by providing ad-hoc customer support }\end{array}$ \\
\hline Customer expansion & $\begin{array}{l}\text { Make additional purchase suggestions that enhance the customer experience } \\
\text { Encourage customers to write a review/testimonial } \\
\text { Encourage customers to refer your business to others } \\
\text { Leverage innovative insights by requesting customers' individual opinions, tastes, or beliefs }\end{array}$ \\
\hline \multicolumn{2}{|l|}{ Relational information processes } \\
\hline Information capture & $\begin{array}{l}\text { Capture customer information from online customer communities and SM } \\
\text { Collect information from SM about the brand and other topics of interest } \\
\text { Capture customer information from CRM systems }\end{array}$ \\
\hline Information integration & $\begin{array}{l}\text { Integrate customer information from different SM } \\
\text { Integrate customer information from different online communication channels (e-mail, website, SM) } \\
\text { Integrate online and offline customer information }\end{array}$ \\
\hline Information use & $\begin{array}{l}\text { Learn about wider customer preferences } \\
\text { Develop customer profiles/segments } \\
\text { Customize offers }\end{array}$ \\
\hline
\end{tabular}

\section{Identified Antecedents of the Intensity of Social CRM Use}

Findings from the content analysis indicate that intensity of social CRM use is influenced by the following antecedents: relative advantage, compatibility technological readiness, top management support, organizational culture environmental pressure.

The relative advantage was indicated to have an influence on the intensity of social CRM use. The results of this study show that SMEs have several benefits of social CRM, including the increase of business value and access to new markets and clients. A manager of the catering provider explained it in the following way: "In the past, we wanted to reach as many prospects as we could but were not as successful as we are now. SM enables us to reach out our customers via different platforms, for instance, TripAdvisor, Pinterest." Furthermore, the findings show that customer feedback helps SMEs to identify new selling opportunities and new customer requirements. For example, a manager of cosmetics producer and retailer stated: "We are always in contact with our prospects and customers and we receive feedback about what they expect from us, what they like, etc."

This study indicates that if social CRM is perceived as compatible with existing processes, the SME will more likely use social CRM intensively. There are two possible explanations for this result. First, SM are compatible with the existing CRM processes and have little learning requirements (Guesalaga, 2016). The following statement of pet supply store owner illustrates the compatibility with existing processes: "From the beginning, we wanted to approach people with similar opinions and interests. We started with a forum. The forum enabled us to give advice and support to pet owners. Lately, the conversation has moved from forum to Facebook." Second, SM can be accessible through web-browsers and mobile devices which make them compatible with existing technologies used by enterprises (Sinclaire \& Vogus, 2011). Creative studio owner confirmed that by the following statement: "As I am self-employed I do not have always access to my computer. 
It happens that I am out of the office for several hours. And during this time I access SM through my mobile device."

Based on study results top management support seems to be another important antecedent of social CRM use intensity. For example, the manager of the catering provider explains it in the following way: "Our CEO completely supports the use of SM and is actively involved in promotional activities." In respect to (social) CRM adoption and use in the SMEs context, Ahani et al. (2017) indicated that support from the management is usually present due to the fact that they make all decisions in the enterprise, from a simple operational to strategic decisions.

Furthermore, organizational culture seems to affect the intensity of social CRM use in SMEs. For instance, Nguyen \& Waring (2013) indicated that SMEs must maintain a culture where employees are recognized as an asset. This is illustrated in the following quote by a manager of the catering provider: "More than half of our employees are engaged in SM activities. For those employees, we have provided directions on how to use SM for managing customer relations. Additionally, we assigned roles for each of them, so everyone knows who publish and manage a particular Facebook page or other SM. Now we are trying to include the remaining employees in order to create a culture where all our employees help us to promote our brands." SMEs, therefore, need to support employees to constantly develop their knowledge and skills and encourage open and two-way communication between different departments to intensify social CRM use.

The findings of this study suggest that technological readiness influences the intensity of social CRM use by SMEs. ICT infrastructure as a potential obstacle towards the intensive use of social CRM was perceived by two of the investigated SMEs. For example, manager of fashion goods retailer stated that "the existing infrastructure is obsolete. We need too much time and specific knowledge for data analysis. Even though our employees are knowledgeable enough, we need a platform that will enable the integration of all channels we use for interaction with prospects and customers."

Additionally, the environmental pressure was identified as an important antecedent of the intensity of social CRM use by SMEs. As pointed out by the manager of sporting goods retailer: "The customers are the main reason. Many people are on SM, which is why we recognized SM as a new medium to get closer to them. It is also necessary to monitor trendsetters and use good approaches to focus customer attention on your brand." Detailed results regarding the number of interviewees referred to specific antecedent as important to the intensity of social CRM use are presented in Table 2.

Table 2

References Made by SMEs to Antecedents of the Intensity of Social CRM Use

\begin{tabular}{|c|c|c|c|c|c|c|c|}
\hline Antecedents & $\begin{array}{l}\text { Creative } \\
\text { studio }\end{array}$ & $\begin{array}{c}\text { Pet supply } \\
\text { store }\end{array}$ & $\begin{array}{l}\text { Catering } \\
\text { provider }\end{array}$ & $\begin{array}{l}\text { Sporting } \\
\text { goods } \\
\text { retailer }\end{array}$ & $\begin{array}{c}\text { Fashion } \\
\text { goods } \\
\text { retailer }\end{array}$ & $\begin{array}{c}\text { Cosmetics } \\
\text { producer } \\
\text { and retailer }\end{array}$ & $\begin{array}{c}\text { Total for } \\
\text { each } \\
\text { anteceden }\end{array}$ \\
\hline Relative advantages & $\mathrm{x}$ & $\mathrm{x}$ & $\mathrm{x}$ & & & $\mathrm{x}$ & 4 \\
\hline Compatibility & $\mathrm{x}$ & $\mathrm{x}$ & & $\mathrm{x}$ & & & 3 \\
\hline Top management support & & $\mathrm{x}$ & $\mathrm{x}$ & $\mathrm{x}$ & $\mathrm{x}$ & $\mathrm{x}$ & 4 \\
\hline Organizational culture & & & $\mathrm{x}$ & & $\mathrm{x}$ & $\mathrm{x}$ & 3 \\
\hline Technology readiness & & $\mathrm{x}$ & & & $\mathrm{x}$ & $\mathrm{x}$ & 3 \\
\hline Environmental pressure & $\mathrm{x}$ & $\mathrm{x}$ & $\mathrm{x}$ & $\mathrm{x}$ & $\mathrm{x}$ & $\mathrm{x}$ & 6 \\
\hline
\end{tabular}

\section{Identified performance outcomes}

This study reports that customer satisfaction and customer loyalty were identified by the majority of interviewees as to be the most important outcomes of the intensity of social CRM use. For example, owner of pet supply store stated: "Our satisfied customers are also the loyal ones. They regularly buy our products. We have also noticed that certain percent of our loyal customers follow us only on SM. We can see from their comments when they are keen to buy new products that we offer." Besides these two customer relationships performance outcomes, other performance outcomes were acknowledged by interviewed SMEs. For instance, digital marketing manager of fashion good retailer identified SM as an additional sales channel, stating that: "While we do not have web store we use SM as an alternative way to sell our products. Namely, we have only several stores where we sell a premium product and because many of our customers are not living near these stores they contact us via SM and ask us for additional information about the specific premium products. Many times SM serves us as a medium where we also close the deal." This statement is related to the statement of marketing manager of cosmetics producer and retailer who indicated that: "SM actually generate sales. We noticed the increased number of customers. Additionally, our existing customers are buying not only one specific product but also other related products. " This indicates that the intensive use of social CRM leads to increased revenue. Additionally, the owner of the creative studio and the digital manager of catering provider pointed out that SM helped them to become more recognizable.

\section{Discussion}

Enterprises need to understand and manage all processes through which relations with customers are evolved (Malthouse et al., 2013; Reinartz et al., 2004; Sigala, 2011). At first, we followed the Reinartz et al. (2004) and Sigala (2011) conceptualization where customer evaluation is part of each sub-dimension (e.g. acquisition, retention), but the results of the qualitative analysis indicated that the customer evaluation is a separated dimension. Therefore, according to the findings, two dimensions emerged in the context of the intensity of social CRM use: (i) customer-facing processes (customer acquisition, customer retention, and customer expansion) and (ii) relational information processes (information capture, information integration, and information use). Customer-facing processes present how SMEs are engaging 
and interacting with customers through acquisition, retention, and expansion processes while relational information processes present how SMEs are managing customer information, both online and offline (see Figure 1). This finding is consistent with Choudhury \& Harrigan
(2014) who studied customer engagement initiatives separately from relational information processes. Therefore, the conceptualization of intensity of social CRM use proposed in this study could be a starting point for further exploration of social CRM use in SMEs.

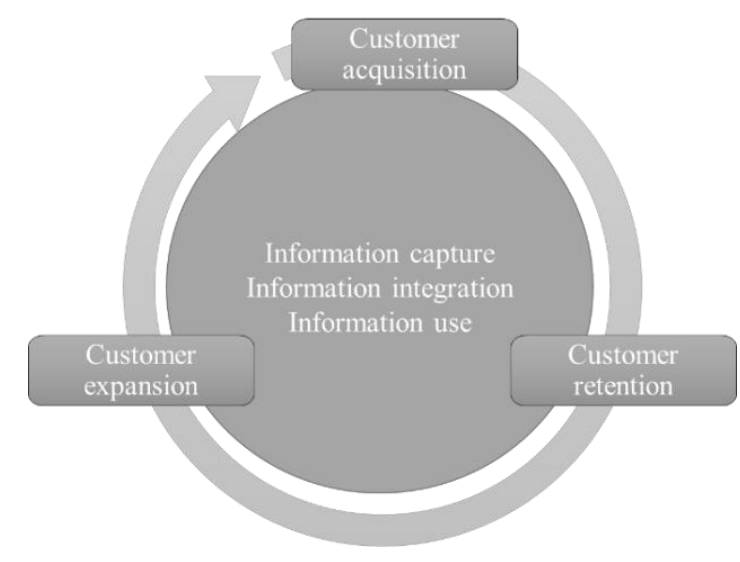

Figure 1. Representation of the Intensity of Social CRM Use

As noted in the previous section, there are several antecedents that may influence the intensity of social CRM use. These antecedents can be classified into the three contexts of TOE framework, which was demonstrated as applicable and useful in several other studies (e.g. Ahani et al., 2017; Hasani et al., 2017).

As a part of the technological context of TOE framework, our study indicates two antecedents that influence the intensity of social CRM use. The first is a relative advantage that was also identified in previous studies exploring the adoption and use of different types of CRM (Alshawi et al., 2011; Law et al., 2013; Sophonthummapharn, 2009) as one of the most important antecedents. The second is compatibility which was also considered as important when exploring CRM adoption and use (Hasani et al., 2017; Law et al., 2013). Hence, our study confirms Ahani et al. (2017) statement that social CRM is compatible with the way SMEs are doing their business.

Three antecedents identified in our study were classified in the organizational context of TOE framework. The first relates to the management support that was also acknowledged by Ahani et al. (2017) and Alshawi et al. (2011) as antecedent that needs to be considered when intensifying the use of social CRM. The second is an organizational culture that was also highlighted as important by several other studies (Law et al., 2013; Nguyen \& Waring, 2013; Rahimi \& Gunlu, 2016; Sigala, 2011). For example, Sigala (2011) suggested that the exploitation of SM for CRM practices requires a substantial cultural shift, which is not perceived as an easy task by SMEs. They need to treat customers as partners and their employees "must be transformed from salesman and information brokers to community builders and consultants" (Sigala, 2011, p. 660). Our study identifies technology readiness as the third antecedent in the organizational context. This is in accordance with previous studies (Ahani et al., 2017; Alshawi et al., 2011; Askool \& Nakata, 2011; King \& Burgess, 2008; Nguyen \& Waring, 2013) indicating that ICT infrastructure and skills have a direct impact on the CRM adoption and use.
The remaining antecedent (environmental pressure) identified in our study was classified in the environmental context of TOE framework. This finding is supported by Hasani et al. (2017) who indicated that external pressure has an effect on social CRM adoption. Furthermore, external pressure has encouraged enterprises to adopt electronic CRM in the travel industry (Gualandris \& Kalchschmidt, 2014) and influenced the decision regarding the mobile CRM adoption (Zheng, 2011).

Regarding the impact of the intensity of social CRM use on the performance outcomes, the customer satisfaction, and customer loyalty were identified in our study as two important performance outcomes that were classified by several authors (e.g. Harrigan et al., 2015; Trainor et al., 2014) as customer relationship performance outcomes. Additionally, we noticed that interviewees who use social CRM more intensively were able to tell more about performance outcomes related to the social CRM use. These findings are consistent with the recent social CRM study (Charoensukmongkol \& Sasatanun, 2017) that showed a positive association between SM use intensity for CRM and business performance satisfaction. Thus, more intensive use of social CRM can improve performance outcomes.

Keramati, Mehrabi, \& Mojir (2010) pointed out that performance outcomes differ among enterprises even though they use the same CRM technologies. However, our study indicates that these differences occur mainly because employees do not have necessary IT skills and expertise to boost the full potential of social CRM. Furthermore, research conducted by Choudhury \& Harrigan (2014) indicated that performance outcomes depend on how well CRM technologies facilitate CRM processes. Based on our research findings it seems that SM can successfully support different CRM processes in SMEs. Nevertheless, the interviewed SMEs are predominantly using social CRM only for developing the enterprise's image and obtaining or responding to customer's opinions, reviews, questions. Furthermore, due to the limited resources and knowledge SMEs are usually not able to integrate and analyse available 
data about customers. Consequently, they are not able to gain holistic insights for further CRM activities.

\section{Conclusions}

Even though SMEs are increasingly using social CRM there is a limited understanding of the patterns of the intensity of social CRM use and its impact on performance outcomes. Therefore, this paper presents practical perspectives on social CRM use based on findings from an exploratory study conducted in six SMEs in Slovenia.

The study offers conceptual clarity to the intensity of social CRM use in SMEs. Based on the literature review and analysed interview transcripts this study offers a twodimensional conceptualization of the intensity of social CRM use in SMEs. Thus, this study extends the theory on customer relationship management by drawing attention to social CRM practices among SMEs. Furthermore, our study revealed that antecedents of the intensity of social CRM use in participating SMEs tend to be very diverse and range from technological, organizational to environmental context. Additionally, data from interviews indicates that more intensive use of social CRM seems to improve relationships with customers.

The study also provides some managerial implications. First, the findings revealed that SMEs need to take into consideration different antecedents that affect the intensity of social CRM use. Second, SMEs perceive social CRM use as a complex set of processes related to engagement with customers through customer-facing processes and management of customer data. While SMEs are using social CRM quite successfully for engagement with customers, they are facing challenges when it comes to management of customers' data. They often lack the abilities to collect, integrate and use comprehensive information about their customers from different communication channels and information systems. Therefore, they often rely on their intuition. Third, findings advocate that SMEs need to use social CRM more intensively in order to have more loyal and satisfied customers. This can only be achieved by strategic use of SM for CRM. According to some of the interviewed SMEs, development and implementation of social CRM strategy is a next important step towards more intensive and successful use of social CRM.

The study has limitations, which highlight opportunities for further research. While the findings are based on the small sample, further research should use larger and more diverse sample of SMEs in order to provide possibilities for generalization of results. Specifically, future research could widen the range of individuals surveyed in the enterprise (not only owners/managers but also other employees). Different roles in the enterprise may reflect different perceptions and practices of SM use for CRM. Moreover, a cross-national study could provide insights regarding cultural differences in adoption decisions and exploitation practices. Furthermore, it would be interesting to deepen the study in a single industry sector (e.g., wholesale and retail, manufacturing, or particular service industry). Additionally, quantitative research could be applied to evaluate and generalize findings of this study. Specifically, future research could explore relationships between antecedents and intensity of social CRM use and intensity of social CRM use and performance outcomes as well as assess the interrelationships among the independent variables.

\section{References}

Ahani, A., Rahim, N. Z. A., \& Nilashi, M. (2017). Forecasting social CRM adoption in SMEs: A combined SEM-neural network method. Computers in Human Behavior, 75, 560-578. https://doi.org/10.1016/j.chb.2017.05.032

Airaksinen, A., Luomaranta, H., Alajaasko, P., \& Roodhuijzen, A. (2015). Statistics on small and medium-sized enterprises. Retrieved February 6, 2017, from http://ec.europa.eu/eurostat/statistics-explained/index.php/Statistics_on_small_and _medium-sized_enterprises

Alshawi, S., Missi, F., \& Irani, Z. (2011). Organisational, technical and data quality factors in CRM adoption - SMEs perspective. Industrial Marketing Management, 40(3), 376-383. https://doi.org/10.1016/j.indmarman.2010.08.006

Askool, S., \& Nakata, K. (2011). A conceptual model for acceptance of social CRM systems based on a scoping study. Ai \& Society, 26(3), 205-220. https://doi.org/10.1007/s00146-010-0311-5

Boulding, W., Staelin, R., Ehret, M., \& Johnston, W. J. (2005). A Customer Relationship Management Roadmap: What Is Known, Potential Pitfalls, and Where to Go. Journal of Marketing, 69(4), 155-166. https://doi.org/10.1509/ jmkg.2005.69.4.155

Cappuccio, S., Kulkarni, S., Sohail, M., Haider, M., \& Wang, X. (2012). Social CRM for SMEs: Current Tools and Strategy. In T. Khachidze, V. Wang, S. Siddiqui, V. Liu, S. Cappuccio, \& A. Lim (Eds.), Contemporary Research on E-business Technology and Strategy (pp. 422-435). Springer Berlin Heidelberg. https://doi.org/10.1007/978-3-642-34447-3_38

Charoensukmongkol, P., \& Sasatanun, P. (2017). Social media use for CRM and business performance satisfaction: The moderating roles of social skills and social media sales intensity. Asia Pacific Management Review, 22(1), 25-34. https://doi.org/10.1016/j.apmrv.2016.10.005

Choudhury, M. M., \& Harrigan, P. (2014). CRM to social CRM: the integration of new technologies into customer relationship management. Journal of Strategic Marketing, 22(2), 149-176. https://doi.org/10.1080/0965254X.2013.876069

Daymon, C., \& Holloway, I. (2010). Qualitative Research Methods in Public Relations and Marketing Communications (2nd ed.). Routledge. Retrieved from http://library.perbanas.ac.id/images/book/PHKI11/qualitativeresearchmethodsinpu blicrelationsandmarketingcommunications.pdf https://doi.org /10.4324/9780203846544 
Durkin, M., McGowan, P., \& McKeown, N. (2013). Exploring social media adoption in small to medium-sized enterprises in Ireland. Journal of Small Business and Enterprise Development, 20(4), 716-734. https://doi.org/10.1108/JSBED-082012-0094

Faase, R., Helms, R., \& Spruit, M. (2011). Web 2.0 in the CRM domain: defining social CRM. International Journal of Electronic Customer Relationship Management, 5(1), 1. https://doi.org/10.1504/IJECRM.2011.039797

Greenberg, P. (2010). The impact of CRM 2.0 on customer insight. Journal of Business Industrial Marketing, 25(6), $410-419$. https://doi.org/10.1108/08858621011066008

Gualandris, J., \& Kalchschmidt, M. (2014). Customer pressure and innovativeness: Their role in sustainable supply chain management. Journal of Purchasing and Supply Management, 20(2), 92-103. https://doi.org/10.1016/j.pursup. 2014.03.001

Guesalaga, R. (2016). The use of social media in sales: Individual and organizational antecedents, and the role of customer engagement in social media. Industrial Marketing Management, 54, 71-79. https://doi.org/10.1016/j.ind marman.2015.12.002

Harrigan, P. (2011). Conceptualising social CRM in SMEs. In Australian and New Zealand Marketing Association Conference. Australian and New Zealand Marketing Association Conference. Retrieved from http://eprints.soton.ac.uk/ 185425/1/ANZMAC_Paper_2011.doc

Harrigan, P., \& Miles, M. (2014). From e-CRM to s-CRM. Critical factors underpinning the Social CRM activities of SMEs. Small Enterprise Research, 21(1).

Harrigan, P., Ramsey, E., \& Ibbotson, P. (2009). Investigating the e-CRM activities of Irish SMEs. Journal of Small Business and Enterprise Development, 16(3), 443-465. https://doi.org/10.1108/14626000910977161

Harrigan, P., Soutar, G., Choudhury, M. M., \& Lowe, M. (2015). Modelling CRM in a social media age. Australasian Marketing Journal (AMJ), 23(1), 27-37. https://doi.org/10.1016/j.ausmj.2014.11.001

Hasani, T., Bojei, J., \& Dehghantanha, A. (2017). Investigating the antecedents to the adoption of SCRM technologies by startup companies. Telematics and Informatics, 34(5), 655-675. https://doi.org/10.1016/j.tele.2016.12.004

Hennig-Thurau, T., Wiertz, C., \& Feldhaus, F. (2015). Does Twitter matter? The impact of microblogging word of mouth on consumers' adoption of new movies. Journal of the Academy of Marketing Science, 43(3), $375-394$. https://doi.org/10.1007/s11747-014-0388-3

Iacovou, C. L., Benbasat, I., \& Dexter, A. S. (1995). Electronic Data Interchange and Small Organizations: Adoption and Impact of Technology. MIS Quarterly, 19(4), 465. https://doi.org/10.2307/249629

Jayachandran, S., Sharma, S., Kaufman, P., \& Raman, P. (2005). The Role of Relational Information Processes and Technology Use in Customer Relationship Management. Journal of Marketing, 69(4), 177-192. https://doi.org/10.150 9/jmkg.2005.69.4.177

Kaplan, A. M., \& Haenlein, M. (2010). Users of the world, unite! The challenges and opportunities of Social Media. Business Horizons, 53(1), 59-68. https://doi.org/10.1016/j.bushor.2009.09.003

Keramati, A., Mehrabi, H., \& Mojir, N. (2010). A process-oriented perspective on customer relationship management and organizational performance: An empirical investigation. Industrial Marketing Management, 39(7), 1170-1185. https://doi.org/10.1016/j.indmarman.2010.02.001

Kim, H.-S. (2012). How CRM strategy impacts organizational performance: Perspective of customer equity drivers. Journal of Database Marketing \& Customer Strategy Management, 19(4), 233-244. https://doi.org/10.1057/dbm.2012.21

Kim, H.-S., \& Kim, Y.-G. (2009). A CRM performance measurement framework: Its development process and application. Industrial Marketing Management, 38(4), 477-489. https://doi.org/10.1016/j.indmarman.2008.04.008

Kumar, V., Choi, J. B., \& Greene, M. (2016). Synergistic effects of social media and traditional marketing on brand sales: capturing the time-varying effects. Journal of the Academy of Marketing Science, 1-21. https://doi.org/10.1007/s11747016-0484-7

Law, A. K. Y., Ennew, C. T., \& Mitussis, D. (2013). Adoption of Customer Relationship Management in the Service Sector and Its Impact on Performance. Journal of Relationship Marketing, 12(4), 301-330. https://doi.org/10.1080/153 32667.2013.846204

Lobato, F., Pinheiro, M., Jacob, A., Reinhold, O., \& Santana, A. (2017). Social CRM: Biggest Challenges to Make it Work in the Real World. In W. Abramowicz, R. Alt, \& B. Franczyk (Eds.), Business Information Systems Workshops (pp. 221232). Springer, Chamng. https://doi.org/10.1007/978-3-319-52464-1_20

Malthouse, E. C., Haenlein, M., Skiera, B., Wege, E., \& Zhang, M. (2013). Managing Customer Relationships in the Social Media Era: Introducing the Social CRM House. Journal of Interactive Marketing, 27(4), 270-280. https://doi.org/10. 1016/j.intmar.2013.09.008

McCann, M., \& Barlow, A. (2015). Use and measurement of social media for SMEs. Journal of Small Business and Enterprise Development, 22(2), 273-287. https://doi.org/10.1108/JSBED-08-2012-0096

Morse, J. (1994). Designing funded qualitative research. In Y. S. Denzin, Norman K. Lincoln (Ed.), Handbook of qualitative research (pp. 220-235). Thousand Oaks, CA, US: Sage Publications, Inc. Retrieved from http://psycnet.ap a.org/psycinfo/1994-98625-012 
Mousavi, S., \& Demirkan, H. (2013). The Key to Social Media Implementation: Bridging Customer Relationship Management to Social Media. In 46th Hawaii International Conference on System Sciences (pp. 718-727). IEEE. https://doi.org/10.11 09/HICSS.2013.531

Nguyen, H. T., \& Waring, S. T. (2013). The adoption of customer relationship management (CRM) technology in SMEs. Journal of Small Business and Enterprise Development, 20(4), 824-848. https://doi.org/10.1108/JSBED-01-2012-0013

Oliveira, T., \& Martins, M. F. (2011). Literature Review of Information Technology Adoption Models at Firm Level. Electronic Journal of Information Systems Evaluation, 14(1), 110-121.

Premkumar, G. (2003). A Meta-Analysis of Research on Information Technology Implementation in Small Business. Journal of Organizational Computing and Electronic Commerce, 13(2), 91-121. https://doi.org/10.1207/S15327744JOCE1302_2

Rahimi, R., \& Gunlu, E. (2016). Implementing Customer Relationship Management (CRM) in hotel industry from organizational culture perspective. International Journal of Contemporary Hospitality Management, 28(1), 89-112. https://doi.org/10.1108/IJCHM-04-2014-0176

Reinartz, W., Krafft, M., \& Hoyer, W. D. (2004). The Customer Relationship Management Process: Its Measurement and Impact on Performance. Journal of Marketing Research, 41(3), 293-305. https://doi.org/10.1509/jmkr.41.3.293.35991

Salciuviene, L., Hopeniene, R., \& Dovaliene, A. (2016). Perceived Corporate Social Responsibility and its Implementation in Practice: The Case of Lithuanian Small and Medium-Sized Enterprises. Inzinerine Ekonomika-Engineering Economics, 27(4), 479-490. https://doi.org/10.5755/j01.ee.27.4.14713

Sashi, C. M. (2012). Customer engagement, buyer-seller relationships, and social media. Management Decision, 50(2), 253272. https://doi.org/10.1108/00251741211203551

Sigala, M. (2011). eCRM 2.0 applications and trends: The use and perceptions of Greek tourism firms of social networks and intelligence. Computers in Human Behavior, 27(2), 655-661. https://doi.org/10.1016/j.chb.2010.03.007

Sigala, M. (2012). Exploiting Web 2.0 for New Service Development: Findings and Implications from the Greek Tourism Industry. International Journal of Tourism Research, 14(6), 551-566. https://doi.org/10.1002/jtr.1914

Sinclaire, J. K., \& Vogus, C. E. (2011). Adoption of social networking sites: an exploratory adaptive structuration perspective for global organizations. Information Technology and Management, 12(4), 293-314. https://doi.org/10.1007/s10799-0110086-5

Sophonthummapharn, K. (2009). The adoption of techno-relationship innovations: A framework for electronic customer relationship management. Marketing Intelligence \& Planning, 27(3), 380-412. https://doi.org/10.1108/026 34500910955254

Srinivasan, R., \& Moorman, C. (2005). Strategic Firm Commitments and Rewards for Customer Relationship Management in Online Retailing. Journal of Marketing, 69(4), 193-200. https://doi.org/10.1509/jmkg.2005.69.4.193

Stelzner, M. (2016). 2016 Social Media Marketing Industry Report. Social Media Examiner.

SURS. (2013). SI-Stat Data Portal. Retrieved May 22, 2017, from http://pxweb.stat.si/pxweb/dialog/statfile1.asp

Tornatzky, L. G., \& Fleischer, M. (1990). The Processes of Technological Innovation. Lexington Books, Lexington, Massachusetts.

Trainor, K. J. (2012). Relating Social Media Technologies to Performance: A Capabilities-Based Perspective. Journal of Personal Selling and Sales Management, 32(3), 317-331. https://doi.org/10.2753/PSS0885-3134320303

Trainor, K. J., Andzulis, J. (Mick), Rapp, A., \& Agnihotri, R. (2014). Social media technology usage and customer relationship performance: A capabilities-based examination of social CRM. Journal of Business Research, 67(6), 1201-1208. https://doi.org/10.1016/j.jbusres.2013.05.002

Vohra, A., \& Neha, B. (2016). A conceptual presentation of customer engagement in the context of social media - An emerging market perspective. International Journal in Management and Social Science, 4(1), 351-366.

Yawised, K., Marshall, P., \& Stockdale, R. (2013). Social CRM: A Review of the Academic and Practitioner Literatures and Research Agendas. In Malaysian Conference on Information Systems (pp. 101-107).

Zheng, V. (2011). The value proposition of adopting mCRM strategy in UK SMEs. Journal of Systems and Information Technology, 13(2), 223-245. https://doi.org/10.1108/13287261111136025

The article has been reviewed.

Received in February, 2018; accepted in September, 2018. 